\title{
AS ABORDAGENS DA GEOGRAFIA SOBRE OS POVOS INDÍGENAS NO BRASIL NOS ÚLTIMOS 10 ANOS
}

\author{
The approaches of geography on indigenous peoples \\ in Brazil in the last 10 years
}

Los enfoques de la geografía de los pueblos indígenas

en Brasil en los últimos 10 años

\author{
Zaira Anislen Ferreira Moutinho * \\ Deyvisson Felipe Batista Rocha ${ }_{* \star}$ \\ * Mestre em Geografia pela Universidade de Brasília (UnB) \\ - zairamoutinho@hotmail.com \\ ** Bacharel em Ciências Sociais pela Universidade Estadual de Montes Claros (UNIMONTES) \\ - deyvisson.unimontes@gmail.com
}

Recebido em 26/09/2019. Aceito para publicação em 08/01/2019.

Versão online publicada em 09/03/2020 (http://seer.ufrgs.br/paraonde)

\begin{abstract}
Resumo:
O objetivo do presente artigo é analisar a produção da ciência geográfica a respeito da problemática dos povos indígenas no Brasil nos últimos 10 anos tendo como base às revistas mais bem avaliadas da área. Com este recorte, foram identificadas seis abordagens diferentes para a questão: a primeira linha reúne os estudos que tiveram como objeto de análise a manutenção, construção e retomada de territórios, tendo sido a identidade cultural apontada como elemento central para a resistência desses povos nessa linha de pesquisa. A segunda linha de pesquisa tem como foco o estudo da relação dos povos indígenas com a conservação da natureza, depreende-se dessas análises que os povos indígenas desempenham um papel central no processo de conservação da natureza no Brasil. A terceira abordagem aglutina os artigos que revelam as práticas espaciais dos povos indígenas, suas representações e organização dos seus territórios. 0 quarto eixo de pesquisa, analisa a expansão do capitalismo sobre os territórios indígenas, desmascara os grandes projetos de "desenvolvimento" ao revelar a expropriação da renda da terra e dos recursos naturais por parte de grandes grupos econômicos. A quinta linha de pesquisa relaciona o surgimento das cidades com o processo de aldeamento dos povos indígenas. A última abordagem, sexta linha, revela as estratégias espaciais de dominação dos povos indígenas no período colonial.
\end{abstract}

Palavras-chave: Povos indígenas. Pesquisas geográficas. Teoria da geografia.

\begin{abstract}
:
The objective of this article is to analyze the production of geographic science regarding the problems of indigenous peoples in Brazil in the last 10 years based on the best evaluated journals in the area. With this cutout, six different approaches to the issue were identified: the first line brings together the studies that had as object of analysis the maintenance, construction and resumption of territories, and the cultural identity was pointed as a central element for the resistance of these peoples in this line of research. The second line of research
\end{abstract}


focuses on the study of the relationship between indigenous peoples and nature conservation, and these analyses show that indigenous peoples play a central role in the process of nature conservation in Brazil. The third approach brings together the articles that reveal the spatial practices of indigenous peoples, their representations and the organization of their territories. The fourth research axis, analyzing the expansion of capitalism over indigenous territories, unmasks large "development" projects by revealing the expropriation of income from land and natural resources by large economic groups. The fifth line of research relates the emergence of cities to the process of aldeamento of indigenous peoples. The last approach, the sixth line, reveals the spatial strategies of domination of indigenous peoples in the colonial period.

Key-words: Indigenous peoples. Geographical surveys. Geography theory.

\begin{abstract}
Resumen:
El objetivo de este artículo es analizar la producción de ciencia geográfica sobre la problemática de los pueblos indígenas en Brasil en los últimos 10 años a partir de las revistas mejor evaluadas de la zona. Con este recorte se identificaron seis enfoques diferentes del tema: la primera línea recoge los estudios que tuvieron como objeto de análisis el mantenimiento, la construcción y la recuperación de territorios, y se señaló la identidad cultural como elemento central para la resistencia de estos pueblos en esta línea de investigación. La segunda línea de investigación se centra en el estudio de la relación entre los pueblos indígenas y la conservación de la naturaleza, y estos análisis muestran que los pueblos indígenas desempeñan un papel central en el proceso de conservación de la naturaleza en Brasil. El tercer enfoque reúne los artículos que revelan las prácticas espaciales de los pueblos indígenas, sus representaciones y la organización de sus territorios. El cuarto eje de investigación, que analiza la expansión del capitalismo sobre los territorios indígenas, desenmascara los grandes proyectos de "desarrollo" al revelar la expropiación de los ingresos de la tierra y los recursos naturales por parte de grandes grupos económicos. La quinta línea de investigación relaciona el surgimiento de las ciudades con el proceso de aldeamiento de los pueblos indígenas. El último enfoque, la sexta línea, revela las estrategias espaciales de dominación de los pueblos indígenas en el período colonial.
\end{abstract}

Palabras-clave: Los pueblos indígenas. Estudios geográficos. Teoría de la geografía.

\title{
1. Introdução
}

A ciência geográfica estruturou ao longo dos últimos séculos um amplo aparato teórico para compreender a realidade, porém, quando se fala da compreensão dos povos nativos, pode-se dizer que a mesma tem-se desenvolvido a passos lentos, sobretudo, neste ponto de sua especificada frente a outras ciências humanas. Mesmo sendo realidade que, dentre as ciências humanas, a antropologia tem uma maior tradição em pensar a situação dos indígenas no Brasil, não se desejando perder essas contribuições, pode ser esta razão que explique o fato dos geógrafos, ao procurarem pensar a problemática indígena, se debrucem imediatamente nas leituras e métodos de pesquisa antropológicos com tanto fervor. Porém, cabe destacar, que a antropologia não é a única disciplina com quem a geografia tem dialogado intensamente para desvendar os conflitos, as práticas espaciais, as fronteiras,

Para0nde!?, Porto Alegre, v.13, n.1, p. 46-58, 2020. http://seer.ufrgs.br/paraonde 
as territorialidades e todas as situações que se relacionam com os nativos dessa uma vez conhecida como Pindorama pelos Tupi Guarani antes da invasão. Então, este trabalho busca responder algumas questões: como tem se desenvolvido as abordagens sobre a questão indígena dentro da geografia? Como essa articulação das disciplinas tem se dado? Em quais direções a geografia pode colaborar? Foi a partir dessas perguntas que se iniciou a escrita desse presente artigo. Ao final foi possível avaliar que existem algumas direções fundamentais para avançar, a primeira delas é questionar a influência da ideia de "integração nacional" sobre as análises. A segunda refere-se a maior operacionalização dos conceitos da geografia para desvendar as geoestratégias em prática na atualidade para tomar os territórios e exterminar essas múltiplas nacionalidades, e por fim a necessidade de desvendar o ensino de geografia nesses contextos tendo em vista principalmente a aprovação da lei de $n^{0}$ 11.645, de 10 de Março de 2008 que dispõem sobre a inclusão no currículo oficial da rede de ensino a obrigatoriedade da temática "História e Cultura Afro-Brasileira e Indígena".

Ressalta-se que o recorte para a realização dessa análise englobou os artigos publicados nas revistas brasileiras disponíveis online melhor classificadas, ou seja, como A1 (Avaliação capes quadriênio 2013-2016) na área de avaliação da Geografia. Com este filtro, encontraram-se apenas quatro periódicos, a se saber: Boletim Goiano de Geografia da Universidade Federal de Goiás, Mercator - Revista de Geografia da Universidade Federal do Ceará, GEOUSP: Espaço e Tempo da Universidade de São Paulo e Sociedade \& Natureza da Universidade Federal de Uberlândia. Este recorte foi definido por incluírem as revistas com maior impacto e capacidade de influência nos programas de pesquisa em geografia. Portanto, este recorte, parte da premissa da maior relevância e possível maior número de acessos dos pesquisadores em revistas com a máxima qualificação na sua área de formação, nesse caso a ciência geográfica. Ou seja, constata-se que isto seja relevante já que além de apontar influências anteriores nas abordagens dos autores que a publicaram, há provavelmente também uma reprodução destas abordagens nos próximos autores que dão preferência a estas fontes sendo um processo que se retroalimenta e hegemoniza uma abordagem ou outra na área sobre um tema específico. Depois de identificados estes quatro periódicos buscou-se em seus respectivos sites as seguintes palavras chave: povos indígenas, indígena(s) e/ou índio(s), encontrando-se na totalidade 24 artigos, posteriormente, sistematizou-se estes 24 artigos os classificando em 6 diferentes abordagens.

\section{Desenvolvimento}

A partir deste recorte foi possível sistematizar seis principais abordagens das pesquisas na geografia sobre os povos indígenas. Porém, cabe o alerta que esta classificação não abarca o todo de cada artigo, mas sim a principal temática que o mesmo aborda, já que, se não fosse feito isso alguns se encaixariam em mais de uma das seis linhas temáticas que os classificamos. A primeira linha está relacionada com a manutenção, construção e retomada de

Para0nde!?, Porto Alegre, v.13, n.1, p. 46-58, 2020. http://seer.ufrgs.br/paraonde 
territórios, essa linha de pesquisa aponta a identidade como elemento central para a resistência desses povos. Utiliza o arcabouço teórico relacionado aos conceitos de etnicidade, identidade, territorialidade. $\mathrm{E}$ a partir desse prisma que discutem os conflitos territoriais. Dentre os artigos dessa linha, o de FERRAZ, NUNES e JUNIOR (2011) analisa o contexto que envolve o conflito estabelecido entre indígenas e proprietários rurais quanto ao uso e necessidade da terra no estado do Mato Grosso do Sul. No referido trabalho, os autores focam a questão da identidade territorial tendo como referencial de abordagem o conceito do "outro", apontando a existência de uma tensão entre culturas; de um lado, aquelas não integradas ao padrão cultural da chamada identidade nacional, ou regional; e de outro, os que assim se identificam a partir dos projetos de modernização econômica e perpetuação do poder local. De acordo com os autores a expansão da fronteira agrícola acentuou uma tensão entre os interesses econômicos dos grandes proprietários de terras e a tentativa de demarcação dos territórios indígenas, especialmente os ocupados pela etnia Guarani. A contribuição significativa do artigo está em evidenciar que as saídas encontradas para a tensão territorial se dá sempre na perspectiva do não índio, que tende a:

(...) tomar o outro, no caso os indígenas, como: ou atrasados que precisam se incorporar aos novos padrões culturais do modo de vida tecnoindustrial dos civilizados urbanos; ou como um grupo cultural injustiçado que precisa ter seu modo de vida tradicional preservado do danoso contato com os brancos. (FERRAZ, NUNES e JUNIOR, 2011, p. 106).

Já o artigo de REIS e GENOVEZ (2013) procura compreender a construção do território do povo Krenak (um dos antigos grupos chamados de botocudos) em Resplendor/MG, no vale do rio Doce, tendo como base os exílios, as diásporas e a reconquista, ocorridos entre 1958 e 1997. Para isso fazem um histórico do conflito pelo território tradicionalmente ocupado pelo povo Krenak com destaque para os seguintes eventos: Carta Régia de 1808; implantação da Estrada de Ferro Vitória-Minas (EFVM), na década de 1910; ações efetuadas pelo extinto Serviço de Proteção ao Índio (SPI) e pelo orgão que o susbtituiu a Fundação Nacional do Índio (FUNAI), além das reconquistas. Analisam as formas organizativas do território dos diversos grupos botocudos e a diáspora dos Krenak. Por fim, concluem que a pretensão do Estado de efetivar uma completa desterritorialização dos Krenak acabou provocando a formação de múltiplos territórios. SEHN DA SILVA E DA SILVA LAROQUE (2012) buscam fazer em seu artigo uma história dos Kaingang considerando os sentidos de sua re(territorialidade) partindo do ponto que mesmo este povo tendo sido expulso pelo Estado os mesmos teriam vivenciado as práticas culturais de sua tradição, sobretudo no que diz respeito a ocupação do território com a continuidade da prática de enterro dos umbigos das crianças onde as mesmas nascem sob as mãos das parteiras deste povo e também o constante movimentar-se no espaço de acordo com suas necessidades e tradição. Já LUSTOSA (2011) analisa a situação de dois povos indígenas (povo Tremembé e povo Jenipapo-Kanindé) frente às diferentes perspectivas de projetos de turismos. Seu artigo destaca a perversa invisibilidade imposta aos povos indígenas do nordeste, especialmente do Ceará. Na sequência avalia como o projeto turístico e residencial "Nova 
Atlântida", capitaneada pelo grupo "Afirma Grupo Imobiliário", que pretende ser um dos maiores complexos de turismo do mundo, pode impactar o povo Tremembé, tornando os recursos naturais indispensáveis para esse povo, como áreas de pesca, inacessíveis. Seu artigo também relata o processo de resistência do povo Jenipapo-Kanindé frente ao projeto "Aquiraz Resort" e a instauração de um turismo de base comunitária indígena. $\mathrm{O}$ artigo traz vários elementos da realidade concreta para a reflexão geográfica, como por exemplo, a cisão interna dos Tremembé frente a cooptação realizado pelos grupos econômicos interessados em suas terras (ainda não homologas), a questão da afirmação da identidade frente aos interesses materiais imediatos dos indígenas, a posição de favorecimento dos grandes grupos econômicos. Refletindo sobre o turismo que incide ou é organizado pelos povos indígenas, a autora conclui que o fenômeno do turismo, no caso do povo Tremembé, acontece de forma predatória sobre o povo indígena e ameaça a sua existência, na medida em que retira toda e qualquer possibilidade desse povo ter poder sobre seu atual território, relegando ao povo Tremembé a posição de meros empregados dos interesses do turismo de massa sem qualquer condição de decisão sobre suas terras. PIMENTEL e RIBEIRO (2016) discutem a criação de unidades de conservação sobre territórios das populações tradicionais e mostra que as concepções conservacionistas são a causa dos conflitos territoriais nessas unidades. Evidencia que as áreas protegidas têm se sustentado em um parâmetro, basicamente, ambiental, mas os agentes e atores sociais envolvidos têm territorialidades e interesses divergentes. SANDOVAL (2015) analisa o processo de ordenamento do território no Equador a partir de 2018. Ilustra a incorporação dos povos indígenas nos processos de decisões à medida que a descentralização avança tendo como base o paradigma do "Bem Viver" que deu subsidio a nova constituição do Equador.

A segunda linha aglutinou as pesquisas com foco na degradação ambiental, serviços ambientais, pressão antrópica sobre terras indígenas e biodiversidade. SANTOS e GOMIDE (2015) procuraram mapear e discutir as pressões da ocupação no entorno das terras Indígenas no estado de Rondônia. As análises de imagens de sensoriamento remoto orbital e álgebra de mapas. Utilizando o Índice de Pressão Antrópica (IPA) o artigo revelou importantes dados a respeito das terras indígenas no estado de Rondônia. $O$ artigo apresenta resultados relevantes como a identificação da pecuária como principal fonte de pressão sobre as terras indígenas, além da geração de diversos mapas sobre o tema. ANGUITA e LEITE (2017) analisam as iniciativas legais tais como leis, projetos de leis, decretos e portarias relacionados com os serviços ecossistêmicos no nosso país. O artigo colabora com a reflexão sobre a situação dos povos indígenas no que tange o pagamento pelos serviços ambientais. Apesar de não tratar especificamente dos povos indígenas em relação a esses pagamentos, fornece inúmeros subsídios para que uma reflexão específica seja desenvolvida. ALMEIDA NETO (2008) procura compreender os sistemas produtivos do povo Katitaurlu o que contribuí para a discussão no sentido de colocar em evidência a necessidade de autonomia dentro dos territórios indígenas e a forma como o global (e seus interesses mercantilistas) ameaça o povo indígena. O principal conceito que aparece

Para0nde!?, Porto Alegre, v.13, n.1, p. 46-58, 2020. http://seer.ufrgs.br/paraonde 
nessas análises é o da paisagem geográfica e suas transformações. Ainda com este enfoque, ZIGLIO e COMEGNA (2013) com a ajuda do arcabouço dos conceitos de "desenvolvimento sustentável" e "racionalidade ambiental" analisam a ação da Confederação dos Povos Indígenas da Bolívia (CIDOB), organização que conta com a participação de 34 povos indígenas da Bolívia. As autoras analisam a ação deste movimento e "sua influência sobre práticas sociais relacionadas à conservação e sustentabilidade dos recursos naturais". (ZIGLIO e COMEGNA, 2013, p. 513). Já no artigo de GOVINDIN e MILLER (2015), são apresentadas as práticas sociais e simbólicas de uma comunidade de pescadores da Baía de Formosa do estado do Rio Grande do Norte. Estas práticas são analisadas com base no uso dos resursos naturais por parte desta comunidade antes e depois da instalação de uma usina sucroalcooleira na região. As autoras destacam no artigo a identificação desta comunidade como similar aos povos indígenas que "desenvolveram modos particulares de existência, adaptados a nichos ecológicos específicos". (GOVINDIN e MILLER, 2015, p. 131). Importante atentar-se ainda no método utilizado pelas autoras com uso da etnografia e da história oral na identificação destas práticas sociais e simbólicas desta comunidade de pescadores.

A terceira linha de pesquisa envolve a discussão sobre identidade, alteridade, práticas socioespaciais e etnoconhecimento. LOSEKANN e WIZNIEWSKY (2012) a partir da análise das práticas de camponeses sulinos, que os autores consideram como um grupo miscigenado constata que apesar da pressão externa produzida pelo capital, as práticas produtivas tradicionais e a relação com o ambiente continuam persistindo, uma vez que seus saberes tradicionais continuam latentes em suas memórias, formas de vida e práticas cotidianas. NUNES e SILVA (2014, p. 93) definem fronteira como "(...) lugar da alteridade, um território de invenção do outro, onde o indivíduo procura se reconhecer frente à alteridade." Suas discussões trazem contribuições para a questão da representação social sobre os povos indígenas que habitam o Mato Grosso do Sul, em especial a cidade de Dourados e os reflexos que essas representações promovem no cotidiano, na medida em que identifica nessas representações o estabelecimento das diferenças que fortalecem a existência conflitos territoriais. SILVA, SILVA e CASTRO (2012) procuram compreender a espacialidade dos caboclos ribeirinhos na Amazônia através do entendimento de seu universo simbólico e as transformações históricas promovidas pelo Estado e pelo avanço do processo de interiorização e modernização na Amazônia. Para os autores "(...) as formas e representações simbólicas são possibilidades que permitem 0 acesso para interpretação das relações de exterioridades das populações caboclas." (SILVA; SILVA; CASTRO, 2012, p. 125). Diante do processo de avanço das transformações, a despeito dos interesses dos caboclos ribeirinhos, no território a possibilidade de reprodução social fica inviável e "até mesmo os jovens perdem o interesse por suas práticas tradicionais". Continua os autores: "diante do processo acelerado de redução da floreta, o caboclo já não consegue mais manter a família como fazia". GOMIDE (2011) analisa a relação do povo Xavante com o Bioma Cerrado. O artigo mostra que o espaço dos Xavante é definido a partir de círculos concêntricos. Além disso, salienta que o número de categorias deste povo usadas para diferenciar a vegetação do cerrado pode chegar a ser maior

Para0nde!?, Porto Alegre, v.13, n.1, p. 46-58, 2020. http://seer.ufrgs.br/paraonde 
do que aquelas dos botânicos que estudaram estas formações. Enfim, o autor faz um vasto levantamento sobre a etnoclassificação dos Xavante sobre o Cerrado. ANJOS (2015) se propõem a desvendar a geografia oficial e como sua constituição se deu a partir do estrangulamento de uma outra geografia pertencentes aos povos indígenas e africanos. Ilustra a riqueza presente nessa geografia que foi invisibilizada pela geografia do Estado. CORREA e CANO (2012) procuram analisar um processo de gestão de recurso hídrico que envolve três atores diferentes (Parque Nacional Natural Nevado del Huila, as Corporações Autônomas Regionais e a comunidade indígena Nasa). Conclui que há uma dificuldade no diálogo de saberes, especialmente por parte dos agentes governamentais e que o conflito em questão são "guerras entre paradigmas conflitos entre formas distintas de entender y sentir el agua" (SHIVA, 2004, p.10, APUD CORREA; CANO, 2012).

A quarta linha tem estudos que discutem os conflitos territoriais utilizando como arcabouço teórico os conceitos relacionados com a renda da terra, território, recursos naturais e apropriação territorial. VASCONCELOS e LIMA (2011) analisam a transformação da terra em mercadoria e o processo de extração da mais-valia a partir da renda da terra no Perímetro Irrigado Baixo Acaraú. Este artigo demonstra como no início da colonização esse processo se deu a partir do extermínio e da violência. O artigo contribui com as reflexões sobre a questão indígena porque traz para cena a problemática da renda da terra. No que se refere à questão indígena, a propriedade privada terra e a possibilidade de comercializá-la vai de encontro à forma de organização socioespacial dos povos indígenas. ALENCAR e DINIZ (2011) retomam a história de luta pela terra no estado do Ceará, para isso resgata as primeiras lutas indígenas no neste estado, em especial dos povos Paioku, Íkos, Jandauí e Karatiu. GORAYEB e BRANNSTROM (2016) fazem uma crítica ao processo de instalação dos parques eólicos no litoral do Ceará, revelando que por trás do discurso da "energia limpa" existe uma total desconsideração pelos impactos provocados aos povos indígenas e um beneficiamento dos grandes grupos produtores e comercializadores de energia eólica. HERRERA e SANTANA (2016) analisam o processo de resistência das famílias ribeirinhas frente à construção da Belo Monte. Demostra como a construção de hidrelétricas tem sucessivamente desrespeitado os direitos dessas populações para garantir a expansão do sistema capitalista. Dentre os processos de resistência está a mobilização dos povos indígenas do Xingu.

A quinta linha relaciona o surgimento das cidades com o processo de aldeamento dos povos indígenas. TEIXEIRA (2008) procura compreender a formação das cidades no estado do Rio Grande do Norte no período colonial. Para isso analisa a organização das missões indígenas como primeiras propulsoras de alguns núcleos urbanos no estado. ALFREDO (2003) analisa a formação da cidade de São Paulo mostrando como o espaço agrário, no período colonial, era organizado a partir da constituição de uma centralidade que o dominasse: o espaço urbano fundamentado pela propriedade privada da terra. Essa foi à estratégia da colônia, que transformava os aldeamentos em uma estratégia para o controle do espaço e da mão de obra, utilizando como meio o processo de formação das cidades.

Para0nde!?, Porto Alegre, v.13, n.1, p. 46-58, 2020. http://seer.ufrgs.br/paraonde 
A sexta linha é composta pelo brilhante e solitário artigo de CHRYSOSTOMO e SANTOS (2016) que desvenda as estratégias geoespaciais utilizadas pelas autoridades das províncias do Rio de Janeiro e Minas Gerais para garantir a colonização das terras indígenas no século XIX. Dentre essas, o estudo aponta que a catequização e civilização dos silvícolas constituíram-se em uma das principais estratégias para dominar os grupos considerados indesejáveis. $O$ artigo traz uma grande contribuição ao demonstrar que o elemento central da dominação "(...) não é apenas um controle sobre o território, mas também sobre o próprio movimento do corpo dos índios, os quais deveriam ser sedentários e apresentar comportamentos ditos civilizados" (CHRYSOSTOMO; SANTOS, 2016, p. 69).

O quadro síntese a seguir apresenta de forma organizada a classificação para os artigos levantados. A classificação levou em conta a abordagens, os principais conceitos utilizados e o periódico ao qual o artigo está vinculado.

QUADRO SÍNTESE 1: Classificação dos artigos por linha de pesquisa das Revistas de Geografia (qualis A1 - quadriênio 2013-2016) e a abordagem dada aos Povos Indígenas nos últimos 10 anos

\begin{tabular}{|c|c|c|c|}
\hline Linha de & Abordagem & Artigos (autores e ano) & Revista \\
\hline \multirow{6}{*}{1} & \multirow{6}{*}{$\begin{array}{l}\text { Manutenção, } \\
\text { construção e } \\
\text { retomada de } \\
\text { territórios. } \\
\text { Apontam a } \\
\text { identidade como } \\
\text { elemento central } \\
\text { para a resistência } \\
\text { dos Povos } \\
\text { Indígenas. }\end{array}$} & $\begin{array}{l}\text { FERRAZ, NUNES e } \\
\text { JUNIOR (2011) }\end{array}$ & $\begin{array}{l}\text { Boletim } \\
\text { Goiano de } \\
\text { Geografia }\end{array}$ \\
\hline & & REIS e GENOVEZ (2013) & $\begin{array}{l}\text { Boletim } \\
\text { Goiano de } \\
\text { Geografia }\end{array}$ \\
\hline & & LUSTOSA (2011) & $\begin{array}{l}\text { Mercator - } \\
\text { Revista de } \\
\text { Geografia da } \\
\text { UFC }\end{array}$ \\
\hline & & $\begin{array}{l}\text { PIMENTEL e RIBEIRO } \\
(2016)\end{array}$ & $\begin{array}{l}\text { GEOUSP: } \\
\text { Espaço e } \\
\text { Tempo }\end{array}$ \\
\hline & & $\begin{array}{l}\text { SEHN DA SILVA E DA } \\
\text { SILVA LAROQUE (2012) }\end{array}$ & $\begin{array}{l}\text { Sociedade \& } \\
\text { Natureza da } \\
\text { UFU }\end{array}$ \\
\hline & & SANDOVAL (2015) & $\begin{array}{l}\text { GEOUSP: } \\
\text { Espaço e } \\
\text { Tempo }\end{array}$ \\
\hline \multirow{3}{*}{2} & \multirow{3}{*}{$\begin{array}{c}\text { Estudo da relação } \\
\text { dos povos } \\
\text { indígenas com a } \\
\text { conservação da } \\
\text { natureza. Povos } \\
\text { indígenas } \\
\text { desempenhando }\end{array}$} & $\begin{array}{l}\text { SANTOS e GOMIDE } \\
(2015)\end{array}$ & $\begin{array}{l}\text { Boletim } \\
\text { Goiano de } \\
\text { Geografia }\end{array}$ \\
\hline & & ANGUITA e LEITE (2017) & $\begin{array}{l}\text { Boletim } \\
\text { Goiano de } \\
\text { Geografia }\end{array}$ \\
\hline & & ALMEIDA NETO (2008) & Mercator - \\
\hline
\end{tabular}




\begin{tabular}{|c|c|c|c|}
\hline & \multirow{3}{*}{$\begin{array}{l}\text { um papel central } \\
\text { no processo de } \\
\text { conservação da } \\
\text { natureza. }\end{array}$} & & $\begin{array}{l}\text { Revista de } \\
\text { Geografia da } \\
\text { UFC }\end{array}$ \\
\hline & & $\begin{array}{l}\text { GOVINDIN e MILLER } \\
(2015)\end{array}$ & $\begin{array}{l}\text { Sociedade \& } \\
\text { Natureza da } \\
\text { UFU }\end{array}$ \\
\hline & & $\begin{array}{l}\text { ZIGLIO e COMEGNA } \\
(2013)\end{array}$ & $\begin{array}{l}\text { Sociedade \& } \\
\text { Natureza da } \\
\text { UFU }\end{array}$ \\
\hline \multirow{6}{*}{3} & \multirow{6}{*}{$\begin{array}{l}\text { Práticas espaciais } \\
\text { dos povos } \\
\text { indígenas, suas } \\
\text { representações e } \\
\text { organização dos } \\
\text { seus territórios. }\end{array}$} & $\begin{array}{l}\text { LOSEKANN e } \\
\text { WIZNIEWSKY (2012) }\end{array}$ & $\begin{array}{l}\text { Boletim } \\
\text { Goiano de } \\
\text { Geografia }\end{array}$ \\
\hline & & NUNES e SILVA (2014) & $\begin{array}{l}\text { Mercator - } \\
\text { Revista de } \\
\text { Geografia da } \\
\text { UFC }\end{array}$ \\
\hline & & $\begin{array}{l}\text { SILVA, SILVA e CASTRO } \\
(2012)\end{array}$ & $\begin{array}{l}\text { Mercator - } \\
\text { Revista de } \\
\text { Geografia da } \\
\text { UFC }\end{array}$ \\
\hline & & GOMIDE (2011) & $\begin{array}{l}\text { GEOUSP: } \\
\text { Espaço e } \\
\text { Tempo } \\
\text { (Online) }\end{array}$ \\
\hline & & ANJOS (2015) & $\begin{array}{l}\text { GEOUSP: } \\
\text { Espaço e } \\
\text { Tempo }\end{array}$ \\
\hline & & CORREA e CANO (2012) & $\begin{array}{l}\text { GEOUSP: } \\
\text { Espaço e } \\
\text { Tempo }\end{array}$ \\
\hline \multirow{4}{*}{4} & \multirow{4}{*}{$\begin{array}{c}\text { Analisa a } \\
\text { expansão do } \\
\text { capitalismo sobre } \\
\text { os territórios } \\
\text { indígenas, } \\
\text { desmascara os } \\
\text { grandes projetos } \\
\text { de } \\
\text { "desenvolvimento" } \\
\text { ao revelar a } \\
\text { expropriação da } \\
\text { renda da terra e } \\
\text { dos recursos } \\
\text { naturais por parte } \\
\text { de grandes grupos } \\
\text { econômicos. }\end{array}$} & $\begin{array}{l}\text { VASCONCELOS e LIMA } \\
\text { (2011) }\end{array}$ & $\begin{array}{l}\text { Mercator - } \\
\text { Revista de } \\
\text { Geografia da } \\
\text { UFC }\end{array}$ \\
\hline & & $\begin{array}{l}\text { ALENCAR e DINIZ } \\
(2011)\end{array}$ & $\begin{array}{l}\text { Mercator - } \\
\text { Revista de } \\
\text { Geografia da } \\
\text { UFC }\end{array}$ \\
\hline & & $\begin{array}{l}\text { GORAYEB e } \\
\text { BRANNSTROM (2016) }\end{array}$ & $\begin{array}{l}\text { Mercator - } \\
\text { Revista de } \\
\text { Geografia da } \\
\text { UFC }\end{array}$ \\
\hline & & $\begin{array}{l}\text { HERRERA e SANTANA } \\
(2016)\end{array}$ & $\begin{array}{l}\text { GEOUSP: } \\
\text { Espaço e } \\
\text { Tempo }\end{array}$ \\
\hline 5 & $\begin{array}{c}\text { Relaciona o } \\
\text { surgimento das }\end{array}$ & TEIXEIRA (2008) & $\begin{array}{l}\text { Mercator - } \\
\text { Revista de }\end{array}$ \\
\hline
\end{tabular}




\begin{tabular}{|c|c|c|c|}
\hline & \multirow{2}{*}{$\begin{array}{l}\text { cidades com o } \\
\text { processo de } \\
\text { aldeamento dos } \\
\text { povos indígenas. }\end{array}$} & & $\begin{array}{l}\text { Geografia da } \\
\text { UFC }\end{array}$ \\
\hline & & ALFREDO (2003) & $\begin{array}{l}\text { GEOUSP: } \\
\text { Espaço e } \\
\text { Tempo }\end{array}$ \\
\hline 6 & $\begin{array}{c}\text { Revela as } \\
\text { estratégias } \\
\text { espaciais de } \\
\text { dominação dos } \\
\text { povos indígenas } \\
\text { no período } \\
\text { colonial. }\end{array}$ & $\begin{array}{l}\text { CHRYSOSTOMO e } \\
\text { SANTOS (2016) }\end{array}$ & $\begin{array}{l}\text { Mercator - } \\
\text { Revista de } \\
\text { Geografia da } \\
\text { UFC }\end{array}$ \\
\hline
\end{tabular}

\section{Considerações Finais}

O levantamento das publicações (últimos 10 anos) nas revistas da Geografia qualis A1 do Brasil sobre indígenas retornou, portanto, apenas 24 artigos. Isso pode indicar que um número reduzido de pesquisas sobre a questão indígena a luz da ciência geográfica fora desenvolvido na última década ou ao menos, se foram empreendidas, não estão nos periódicos mais bem avaliados da área. Porém é importante considerar dois pontos nesta conclusão: primeiro, a interdisciplinaridade pela complexidade e diversidade da realidade dos povos indígenas o que pode fazer pesquisadores da geografia publicarem seus artigos em revistas não restritas a sua àrea de formação, tais como períodicos da própria antropologia ou especializados somente na questão indígena sem se fechar a um campo específico do pensamento científico; segundo, tem a questão da maioria dos povos indígenas no Brasil habitarem o norte do país região, região que não tem em suas Universidades, nos programas de pesquisa da geografia periódicos com a qualificação máxima da Coordenação de Aperfeiçoamento de Pessoal de Nível Superior (CAPES). Este último ponto ainda é claramente percebido quando se observa que dos mais de 300 povos indígenas que habitam o território Brasileiro há milênios, não houveram pesquisas diretamente com povos indígenas do Norte do Brasil, mas sim, nos Guarani do Mato Grosso do Sul; nos Kaingang do Rio Grande do Sul, nos Xavante e nos Katitaurlu (sub grupo dos Nambikwara) e nos povos do Xingu do Mato Grosso e nos Krenak (um dos grupos originados dos antigos botocudos) de Minas Gerais, além do estudo em documentos históricos sobre os Tremembé, os Jandauí, os Karatiu, os Jenipapo-Kanindé, os Paioku e os Íkos do Ceará. Levando em conta estes apontamentos e estas ressalvas, pode-se dizer que nos últimos dez anos a geografia não deu conta de apresentar para a sociedade uma análise que englobe essa totalidade ou que revele a distribuição dos conflitos envolvendo os diversos povos indígenas, tão pouco disponibilizou uma análise em escala nacional, já que as pesquisas que chegaram para a publicação em periódicos qualificados como A1 foram 
realizadas nos estados do Mato Grosso do Sul, Mato Grosso, Pará, Amazonas, Rondônia, Ceará, Minas Gerais, Rio Grande do Sul, Rio Grande do Norte e São Paulo.

Neste artigo, esses parcos 24 artigos foram agrupados em seis abordagens diferentes. Esse agrupamento revelou a maior presença de publicações na linha temática 1 que, em suma, apontam para a manutenção, construção e retomada de territórios apontando a identidade como elemento central para a resistência dos Povos Indígenas; e a linha temática 3 que apresentam as práticas espaciais dos povos indígenas, suas representações e organização dos seus territórios. Isto indica que a geografia cultural ou pelo menos seu arcabouço teórico tem dado maior ênfase para essa temática. Assim, os conflitos territoriais e a formação de territórios têm sido explicados dentro da geografia a partir da interlocução direta, sobretudo com a antropologia e seus métodos de pesquisa. Já, por exemplo, a abordagem da linha temática 6 que revela as estratégias espaciais de dominação dos povos indígenas no período colonial foi sustentada por um único artigo. Além disso, foi possível identificar um vazio de publicações sobre as seguintes temáticas: ensino de geografia no contexto indígena, e uma análise sobre as estratégias espaciais de dominação dos territórios indígenas em curso no momento presente. Por fim, analisar o território enquanto elemento central para sobrevivência das nações indígenas, ou seja, a tomada dos territórios indígenas pode significar não somente 0 saque dos recursos naturais ou o extermínio práticas culturais, mas o fim de nações (organizações políticas, econômicas, sociais e culturais). A abordagem da geografia pode colaborar com esse problema se colocar em evidência o sentido de nações e toda a autonomia e independência que cerca essa questão e abandonar a ideia de "integração" que as análises e pensamentos sobre os povos indígenas são costumamente submetidos.

\section{Referências}

ALENCAR, Francisco Amaro Gomes de; DINIZ, Aldiva Sales. MST - CEARÁ, 20 ANOS DE MARCHA (MST-Ceará, 20 years of marchs). Mercator, Fortaleza, v. 9, n. 20, p. 133 a 148, jan. 2011. ISSN 1984-2201.

ALFREDO, Anselmo. Constituição do Espaço Urbano de São Paulo (Brasil). Aspectos sobre a Problemática Indígena na relação contraditória cidade campo. GEOUSP: Espaço e Tempo (Online), São Paulo, n. 13, p. 107-126, june 2003. ISSN 2179-0892.

ALMEIDA NETO, Prudente Pereira de. OS SISTEMAS AGROFLORESTAIS DOS KATITAURLU: território dos saberes, Geografia da biodiversidade (the agriforest systems of Katitaurlu: territory of knowledge, geography and biodiversity). Mercator, Fortaleza, v. 3, n. 5, nov. 2008. ISSN 1984-2201.

ANGUITA, P. M. de; LEITE, M. B. Classificação das políticas públicas relacionadas com os serviços ecossistêmicos no território brasileiro. Bol. Goia. Geogr. (Online). Goiânia, v. 37, n. 1, p. 106-121, jan./abr. 2017. ISSN: 19848501. 
ANJOS, Rafael Sanzio Araújo. As geografias oficial e invisível do Brasil: algumas referências.GEOUSP: Espaço e Tempo (Online), São Paulo, v. 19, n. 2, p. 374-390, nov. 2015. ISSN 2179-0892.

CHRYSOSTOMO, Maria Isabel de Jesus; SANTOS, Higor Mozart Geraldo. POLÍTICA TERRITORIAL NOS SERTÕES DOS ÍNDIOS, SÉCULO XIX /// III TERRITORIAL POLITICS IN NATIVE-BRAZILIAN BACKWOODS, XIX CENTURY. Mercator, Fortaleza, v. 15, n. 1, p. 55-71, jan. 2016. ISSN 19842201.

CORREA, Diana Magaly; CANO, Marlenny Díaz. TENSÃO ENTRE JUSTIÇA SOCIAL E JUSTIÇA AMBIENTAL NA GESTÃO DA ÁGUA: O CASO DA BACIA DO RIO PALO.GEOUSP: Espaço e Tempo (Online), São Paulo, n. 31, p. 120131, aug. 2012. ISSN 2179-0892.

FERRAZ, C. B. O.; NUNES, F. G.; JUNIOR, J. L. A. Identidade cultural e a construção do "outro" em mato grosso do sul - o conflito entre indígenas e fazendeiros. B.goiano.geogr. Goiânia, v. 31, n. 2, p. 99-112, jul./dez. 2011.

GENOVEZ, P.F.; REIS, R. C. Território sagrado: exílio, diáspora e reconquista krenak no vale do rio doce, resplendor, mg. Bol. Goia. Geogr. (Online). Goiânia, v. 33, n. 1, p. 1-15./jan/abr. 2013. ISSN: 1984-8501.

GOMIDE, Maria Lucia Cereda. Ró - Cerrados e Mundo A'uwe Xavante. GEOUSP: Espaço e Tempo (Online), São Paulo, n. 29, p. 117-130, dec. 2011. ISSN 2179-0892.

GORAYEB, Adryane; BRANNSTROM, Christian. CAMINHOS PARA UMA GESTÃO PARTICIPATIVA DOS RECURSOS ENERGÉTICOS DE MATRIZ RENOVÁVEL (PARQUES EÓLICOS) NO NORDESTE DO BRASIL /// III TOWARD PARTICIPATORY MANAGEMENT OF RENEWABLE ENERGY RESOURCES (WIND-FARM) IN NORTHEASTERN BRAZIL. Mercator, Fortaleza, v. 15, n. 1, p. 101-115, mar. 2016. ISSN 1984-2201.

GOVINDIN, J. L. DOS S.; MILLER, F. DE S. Práticas sociais e simbólicas: comunidade de pescadores e unidade de conservação em Baía Formosa/RN / Práticas sociais e simbólicas: comunidade de pescadores e unidade de conservação em Baía Formosa/RN. Sociedade \& Natureza, Uberlândia, v. 27, n. 1, 19 maio 2015.

HERRERA, José Antonio; SANTANA, Nelivaldo Cardoso. Empreendimento hidrelétrico e famílias ribeirinhas na Amazônia: desterritorialização e resistência à construção da hidrelétrica Belo Monte, na Volta Grande do Xingu.GEOUSP: Espaço e Tempo (Online), São Paulo, v. 20, n. 2, p. 250-266, aug. 2016. ISSN 2179-0892.

LOIOLA VASCONCELOS, Tereza Sandra; CRUZ LIMA, Luiz. TERRAMERCADORIA NO AGRONEGÓCIO CEARENSE (the land-merchandise in the agrobusiness to the state of Ceará - Brazil). Mercator, Fortaleza, v. 10, n. 22, p. p. 123 a 136, july 2011. ISSN 1984-2201.

LOSEKANN M B B.; WIZNIEWSKY, C. R. F. Saber e identidade dos agricultores familiares camponeses de costa do bica e paredão, piratini (rs). B goiano.geogr. Goiânia, v. 32, n. 2, p. 33-49, jul./dez. 2012. 
LUSTOSA, Isis Maria Cunha. PROJETOS DE TURISMO EM TERRAS INDÍGENAS: Tremembé de Itapipoca e Jenipapo-Kanindé de Aquiraz - Ceará. Mercator, Fortaleza, v. 9, n. 20, p. 149 a 162, jan. 2011. ISSN 1984-2201. Disponível em: <http://www.mercator.ufc.br/mercator/article/view/282>. Acesso em: 05 dez. 2017.

NUNES, Flaviana Gasparotti; SILVA, Solange Rodrigues da. FRONTEIRA E CONSTRUÇÃO DO "OUTRO": concepções de alunos sobre povos indígenas (the border and the construction of the "other": conceptions from elementary school students about the indigenous peoples). Mercator, Fortaleza, v. 13, n. 1, p. 93 a 106, apr. 2014. ISSN 1984-2201.

PIMENTEL, Márcia Aparecida Silva; RIBEIRO, Wagner Costa. Populações tradicionais e conflitos em áreas protegidas. GEOUSP: Espaço e Tempo (Online), São Paulo, v. 20, n. 2, p. 224-237, aug. 2016. ISSN 2179-0892.

SANDOVAL, María Fernanda López. El Sistema de Planificación y el Ordenamiento Territorial para Buen Vivir en el Ecuador. GEOUSP: Espaço e Tempo (Online), São Paulo, v. 19, n. 2, p. 296-311, nov. 2015. ISSN 21790892.

SANTOS, A M.; GOMIDE, M L C.; A Ocupação no entorno das terras indígenas em Rondônia, Brasil. Bol. Goia. Geogr. (Online). Goiânia, v. 35, n. 3, p. 417436, set./dez. 2015. ISSN: 1984-8501.

SEHN DA SILVA, J. B.; DA SILVA LAROQUE, L. F. A história dos Kaingang da Terra Indígena Linha Glória, Estrela, Rio Grande do Sul/Brasil: Sentidos de sua (re)territorialidade / The history of Kaigang people from Linha Glória indigenous land, Estrela, Rio Grande do Sul/Brazil: Senses of their (re)ter.. Sociedade \& Natureza, Uberlândia, v. 24, n. 3, p. 435-448, 11 dez. 2012.

SILVA, Josué da Costa; SILVA, Adnilson de Almeida; CASTRO, Sheila. NOVAS ESPACIALIDADES E ORGANIZAÇÕES NA VIVÊNCIA DO RIBEIRINHO NA AMAZÔNIA (spatiality and organizations new in ribeirinho the experience of the amazon). Mercator, Fortaleza, v. 11, n. 26, p. 121 a 130, oct. 2012. ISSN 1984-2201.

TEIXEIRA, Rubenilson Brazão. THE NAMES OF CITY IM COLONIAL BRAZIL. CONSIDERATIONS OFTER CAPTAINY THE RIO GRANDE DO NORTE. Mercator, Fortaleza, v. 2, n. 3, nov. 2008. ISSN 1984-2201.

ZIGLIO, L. A. I.; COMEGNA, M. A. Movimentos socioambientais e gestão dos recursos naturais no cenário amazônico: Ações da Confederação dos Povos Indígenas na Bolívia / Social environmental movements and management natural resources in the Amazon scenario: Action of indigenous....

Sociedade \& Natureza, Uberlândia, v. 25, n. 3, p. 513-523, 10 dez. 2013. 